\title{
Pemodelan Dispersi Debu Industri Semen di Kabupaten Tuban Jawa Timur
}

\author{
Ardhi Rahmadhani, Joni Hermana, dan Abdu Fadli Assomadi \\ Departemen Teknik LIngkungan, Fakultas Teknik Sipil, Lingkungan dan Kebumian, Institut \\ Teknologi Sepuluh Nopember (ITS) \\ e-mail: hermana@enviro.its.ac.id
}

\begin{abstract}
Abstrak-Aktivitas ndustri semen menghasilkan emisi berupa debu yang berpotensi menimbulkan pencemaran lingkungan. Persebaran debu di lingkungan dipengaruhi oleh faktor meteorologi. Dalam penelitian telah dianalisis kuantitas emisi debu dari cerobong industri semen dan pola sebarannya pada periode rata-rata musim kemarau dan musim hujan. Pola dispersi debu di area sekitar industri diestimasi menggunakan persamaan umum model Gauss. Karakteristik udara menggunakan data iklim dari stasiun meteorologi Juanda, periode pengamatan tahun 2016 sampai tahun 2017. Perhitungan konsentrasi ambien dilakukan pada setiap titik dengan perubahan 100 meter searah angin (sumbu-x) dan arah tegak lurus arah angin (sumbu-y) dari masing-masing titik cerobong. Hasil ini kemudian dianalisis dan digambarkan dalam peta kontur konsentrasi yang dioverlay pada peta wilayah penelitian. Hasil penelitian menunjukkan pola angin pada kondisi atmosfer rata-rata musim kemarau (bulan April hingga September) dominan ke arah timur dengan kondisi kelas stabilitas atmosfer $B$ diperoleh konsentrasi sebaran debu tertinggi adalah $444,26 \mu \mathrm{g} / \mathrm{m}^{3}$ sedangkan pola angin pada kondisi atmosfer rata-rata musim hujan (bulan Oktober hingga Maret) dominan ke arah barat dengan kondisi kelas stabilitas atmosfer $C$ diperoleh konsentrasi sebaran tertinggi adalah $547,24 \mu \mathrm{g} / \mathrm{m}^{3}$.
\end{abstract}

Kata Kunci-Debu, Dispersi, Gauss, Majemuk, Semen.

\section{PENDAHULUAN}

$\mathrm{E}$ MISI dominan yang dihasilkan dari proses pembuatan semen adalah partikel berupa debu dan gas seperti $\mathrm{SO}_{2}$, $\mathrm{NO}_{2}$ [1]). Debu merupakan partikulat padat yang berukuran antara 1-100 mikron [2]. Pencemaran udara dapat berakibat negatif terhadap lingkungan, antar lain dampak fisik atmosfer, ekonomi, vegetasi, flora fauna, kesehatan manusia, dan estetika [3]. Hasil penelitian terdahulu menunjukkan paparan debu terhirup berkorelasi dengan gangguan fungsi paru serta probabilitas terjadinya gangguan fungsi paru pada responden di tempat kerja [4].

Berdasarkan data meteorologi Kabupaten Tuban tahun 2017 kecepatan angin berkisar antara 1,1-3 m/s di pagi hari dan 3$3,9 \mathrm{~m} / \mathrm{s}$ pada sore hari [5]. Kondisi kecepatan angin dan kekuatan radiasi serta lama penyinaran yang cukup tinggi di Kabupaten Tuban, menyebabkan suhu udara tinggi dan menyebabkan turbulensi mekanis arah vertikal lebih baik, sehingga menyebabkan penekanan lapisan inversi ke level yang lebih tinggi dan area mixing height lebih

luas [6]. Melalui model dispersi, dapat diperkirakan konsentrasi polutan di berbagai titik berdasarkan kondisi meteorologi daerah bersangkutan menggunakan perhitungan numeris [7]. Gaussian plume model adalah model matematika yang digunakan untuk mempresentasikan proses dispersi polutan di udara seperti NOx, SOx dan debu terutama dari sumber titik seperti dispersi di sekitar cerobong asap untuk mengestimasi impact polutan non-reaktif dari sumber titik atau garis [1] [8] [9].

Penelititan ini bertujuan untuk mendapatkan pola persebaran emisi berupa debu berdasarkan model sebaran Gauss pada periode musim hujan dan kemarau serta mengetahui nilai konsentrasi maksimum pencemar berupa debu berdasarkan model sebaran Gauss yang berasal dar sumber industri semen.

\section{METODE PENELITIAN}

\section{A. Pengumpulan Data}

Pengumpulan data dilakukan dengan mengumpulkan referensi yang diperoleh dari didapatan dari jurnal, text book, dan sumber lainya yang berkaitan dengan dispersi polutan berupa debu di udara.

Data sekunder yang digunakan untuk analisis sebaran polutan adalah sebagai berikut:

1. Data emisi debu dari cerobong industri semen Kabupaten Tuban dalam kurun waktu satu bulan terakhir tahun 2016.

2. Data kondisi meteorologi Kabupaten Tuban berupa data harian kecepatan angin dalam satu tahun terakhir (2016-2017) yang berasal dari BMKG Juanda.

3. Data pengukuran kualitas udara ambien di sekitar wilayah ndustr semen.

4. Data posisi dan level ketinggian titik penerima polutan yang berasal dari Googl Earth.

Data yang digunakan untuk analisis persebaran debu adalah rata-rata beban emisi dalam satu bulan dan kondisi rata-rata meteorologi dalam satu tahun.

\section{B. Metode Analisis}

1. Identifikasi Faktor Meteorologi

Identifikasi terhadap faktor meteorologi dilakukan dengan cara menghitung nilai rata-rata kecepatan angin, arah angin serta temperatur udara pada periode bulan hujan (Oktober-Maret) dan periode bulan kemarau (Maret-September) hasil pengukuran BMKG Juanda.

2. Penentuan Lokasi Titik Penerima Sebaran Polutan 
Lokasi titik penerima sebaran polutan disusun dalam jarak antar masing-masing titik lokasi adalah 100 meter serah arah angin dan 100 meter tegak lurus arah angin dengan ketinggian 1,5 meter dari permukaan tanah.

3. Perhitungan Konsentrasi Sebaran Polutan

Metode perhitungan sebaran polutan dari sumbe cerobong digunakan rumus Gaussian Plume Model.

$C\left(x_{1}, y, z, H\right)=\frac{Q}{2 \pi \sigma_{y} \sigma_{z} u} \exp \left[-\frac{1}{2}\left(\frac{y}{\sigma_{y}^{2}}\right)\right]\left\{\exp \left[-\frac{1}{2}\left(\frac{z-H}{\sigma_{z}^{2}}\right)^{2}\right]+\exp \left[-\frac{1}{2}\left(\frac{z+H}{\sigma_{z}^{2}}\right)^{2}\right]\right\}$

Keterangan :

$C \quad$ : konsentrasi polutan pada suatu titik $(x, y, z)$, dalam $\mathrm{gm}^{-3}$

$Q \quad$ : laju emisi, dalam $\mathrm{gs}^{-1}$

$\sigma y \quad:$ koefisien penyebaran horisontal ( $y$ ), dalam $\mathrm{m}$

$\sigma z \quad$ : koefisien penyebaran vertikal ( $z$ ), dalam $\mathrm{m}$

$u$ : kecepatan angin rata-rata pada ketinggian cerobong, dalam $\mathrm{ms}^{-1}$

$x \quad$ : kepulan horisontal dari sumber pencemar searah arah angin, dalam $\mathrm{m}$

$y \quad$ :kepulan horisontal tegak lurus arah angin, dalam $\mathrm{m}$

$z \quad$ :kepulan vertikal dari permukaan, dalam $\mathrm{m}$

$H \quad$ : ketinggian efektif $(H=h+\Delta h)$, dalam $\mathrm{m}$

$h$ : ketinggian cerobong, dalam $\mathrm{m}$

$\Delta h \quad$ : tinggi kepulan di atas cerobong, dalam m

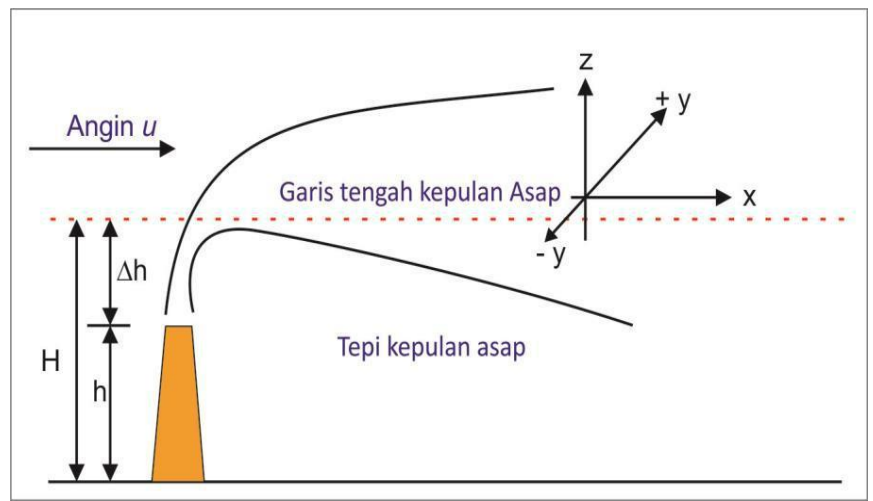

Gambar 1. Ilustrasi Model Penyebaran Polutan dari Sumber Titik Berdasar Sebaran Gauss

\section{ANALISIS DAN PEMBAHASAN}

\section{A. Karakteristik Sumber Emisi}

Sumber emisi berasal dari aktivitas industri semen yang dikeluarkan melalui cerobong. Sumber emisi berasal dari unit pengolahan yang berjumlah enam cerobong dengan karakteristik yang berbeda. Profil masing-masing cerobang dapat dilihata pada Tabel 1 dan Tabel 2.

Tabel 1.

Profil Cerobong Unit Pengolahan 1

\begin{tabular}{lccc}
\hline \hline \multicolumn{1}{c}{ Parameter } & Cerobong & Cerobong & Cerobong \\
& A & B & C \\
\hline Tinggi Cerobong $(\mathrm{m})$ & 108,8 & 29,65 & 43,5 \\
Diameter $(\mathrm{m})$ & 4,2 & 2 & 2,55 \\
Kecepatan alir $(\mathrm{m} / \mathrm{s})$ & 12,5 & 7 & 10 \\
Suhu Cerobong $(\mathrm{C})$ & 130 & 80 & 75 \\
Elevasi sumber $(\mathrm{mdpl})$ & 33 & 33 & 33
\end{tabular}

Konsentrasi Emisi

$\operatorname{Rata} 2\left(\mathrm{mg} / \mathrm{m}^{3}\right)$

Beban emisi ( $\mathrm{g} / \mathrm{s})$

4,68

7,9

24,46

0,81

0,17

1,25

\section{B. Analisis Data Meteorologi}

1. Suhu Udara

Suhu udara rata-rata bulanan pada periode musim hujan (Oktober-Maret) di Kabupaten Tuban adalah 27,4 C sedangkan suhu udara rata-rata bulanan pada periode musim kemarau (April-September) adalah 28,1 C.

2. Arah dan Kecepatan Angin

Kecepatan angin rata-rata bulanan di Kabupaten Tuban pada musim hujan adalah $3,6 \mathrm{~m} / \mathrm{s}$ ke arah Timur sementara pada musim kemarau kecepatan angin rata-rata adalah 3,8 $\mathrm{m} / \mathrm{s}$ ke arah Barat.

3. Stabilitas Atmosfer

Kemantapan (stabilitas) udara Pasquill secara periodik di Kabupaten Tuban pada musim kemarau dan musim hujan dari hasil analisis stabilitas atmosfer diperoleh bahwa stabilitas mempunyai variasi antara B (tidak stabil) pada musim kemarau dan stabilitas C (sedikit stabil) pada musim hujan.

\section{Perhitungan Konsentrasi Sebaran Polutan}

Perhitungan nilai konsentrasi dilakukan pada titik penerima yang telah direncanakan. Perhitungan konsentrasi emisi berdasarkan persamaan Gauss. Perhitungan dilakukan pada masing-masing sumber emisi terhadap titik penerima yang selanjutnya nilai konsentrasi dari setiap sumber ke titik resptor akan diakumulasikan.

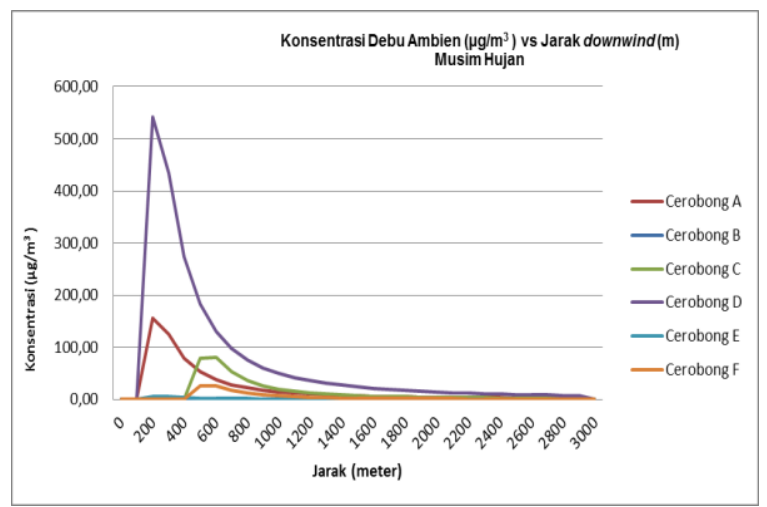

Gambar 2. Grafik Sebaran Konsentrasi Debu Pada Musim Hujan Pada Centerline $(y=0 \mathrm{~m})$

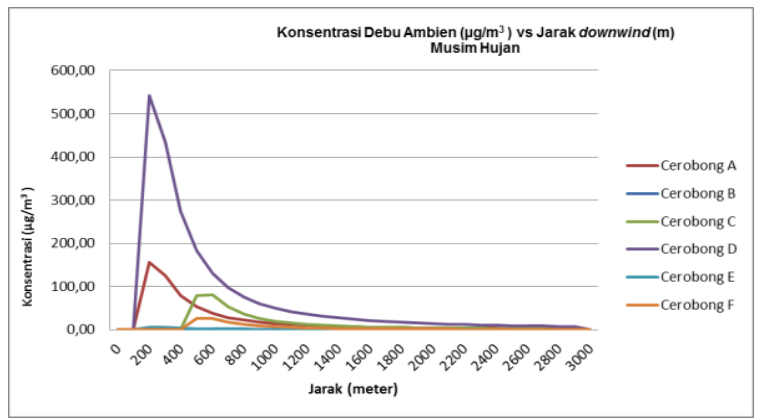

Gambar 3. Grafik Sebaran Konsentrasi Debu Pada Musim Kemarau Pada Centerline $(y=0 \mathrm{~m})$ 
Pada Gambar 2 dan Gambar 3 dapat dilihat bahwa konsentrasi debu yang diterima oleh titik penerima pada musim kemarau dari setiap sumber titik sumber cenderung lebih rendah dibandingkan dengan konsentrasi debu yang diterima oleh titik penerima pada musim hujan. Hal ini disebabkan karena perbedaan faktor cuaca yang meliputi suhu, kecepatan angin dan penyinaran matahari yang berbeda antara musim hujan dan kemarau. Faktor cuaca berpengaruh terhadap penentuan kelas stabilitas yang digunakan sebagai koefisien dalam perhitungan model. Selain itu faktor ketinggian titik penerima dari muka tanah juga terdapat perbedaan antara wilayah penerima emisi musim hujan (sisi timur industri) dan penerima emisi musim kemarau (sisi barat industri). Tinggi cerobong berpengaruh terhadap nilai sebaran polutan. Semakin tinggi cerobong maka sebaran emisi akan lebih meluas hal ini dikarenakan semakin tinggi suatu tempat maka tekanan udara ke bawah akan semakin berkurang serta angin yang bergerak semakin cepat sehingga menyebabkan emisi debu dapat terdispersi cukup luas [10]. Sebaran polutan dengan konsentrasi tertinggi pada musim hujan dan kemarau terdapat pada jarak kurang dari 1000 meter dari seumber pencemar.

Sebaran debu yang bersumber dari setiap cerobong menghasilkan konsentrasi debu tertinggi pada posisi koordinat yang berbeda. Nilai akumulasi sebaran debu tertinggi dihitung secara simultan dari seluruh sumber pada musim hujan terdapat pada titik koordinat (598277,4 m; 9246348 m) dengan konsentrasi $547,24 \mu \mathrm{g} / \mathrm{m}^{3}$ sedangkan pada musim kemarau terdapat pada titik koordinat (597477,4 m; $9246348 \mathrm{~m})$ dengan konsentrasi 444,26 $\mu \mathrm{g} / \mathrm{m}^{3}$. Hasil perhitungan konsentrasi sebaran debu tertinggi yang bersumber dari setiap cerobong terdapat pada Tabel 3 dan Tabel 4.

Tabel 3.

Konsentrasi Sebaran Debu Tertinggi dari Setiap Sumber Pada Musim Hujan

\begin{tabular}{lrcc}
\hline \hline & \multirow{2}{*}{$\begin{array}{c}\text { Konsentrasi Debu } \\
\left(\mu \mathrm{g} / \mathrm{m}^{3}\right)\end{array}$} & \multicolumn{2}{c}{ Koordinat } \\
\cline { 3 - 4 } Sumber Emisi & 132,17 & $\mathrm{X}(\mathrm{m})$ & $\mathrm{Y}(\mathrm{m})$ \\
\hline Cerobong A & 0,0000135 & 597477,4 & 92465478 \\
Cerobong B & 79,94 & 598277,4 & 9246448 \\
Cerobong C & 542,18 & 597877,4 & 9246548 \\
Cerobong D & 5,74 & 597877,4 & 9246348 \\
Cerobong E & 26,44 & 598277,4 & 9246348 \\
Cerobong F & &
\end{tabular}

Tabel 4.

Konsentrasi Sebaran Debu Tertinggi dari Setiap Sumber Pada Musim Kemarau

\begin{tabular}{lrcc}
\hline \hline & \multirow{2}{*}{$\begin{array}{c}\text { Konsentrasi Debu } \\
\left(\mu \mathrm{g} / \mathrm{m}^{3}\right)\end{array}$} & \multicolumn{2}{c}{ Koordinat } \\
\cline { 3 - 4 } Sumber Emisi & 155,32 & $\mathrm{X}(\mathrm{m})$ & $\mathrm{Y}(\mathrm{m})$ \\
\hline Cerobong A & 13,81 & 597477,4 & 9246548 \\
Cerobong B & 82,46 & 597777,4 & 9246448 \\
Cerobong C & 432,35 & 597477,4 & 9246548 \\
Cerobong D & 5,86 & 597477,4 & 9246348 \\
Cerobong E & 27,27 & 597777,4 & 9246348 \\
Cerobong F & & \\
\hline \hline
\end{tabular}

\section{Kontur Dispersi Polutan}

Gambar kontur dispersi hasil overlay dengan peta dari Google Earth dapat dilihat bahwa sebagian besar debu jatuh di wilyah sekitar industri. Penggambaran kontur konsentrasi debu di udara ambien hasil overlay software Surfer 10 dapat dilihat pada Gambar 5 dan Gambar 6. Skala konsentrasi pada gambar kontur digambarkan melalui gradas warna. Konsentrasi rendah hingga tinggi digambarkan dengan warna biru muda hingga warna ungu.

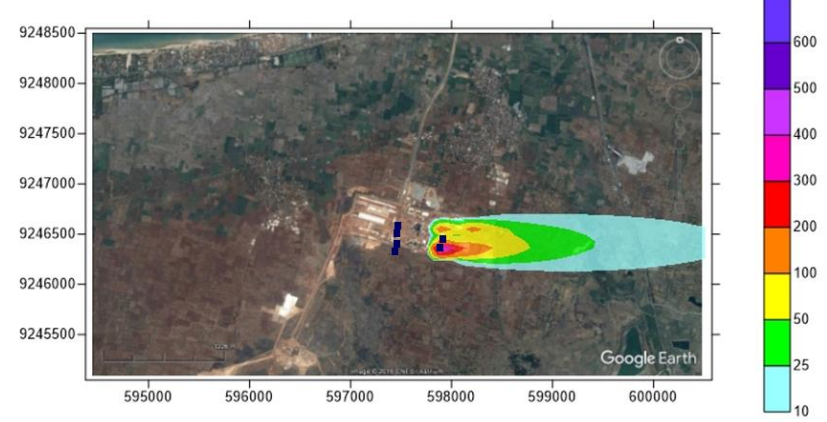

Gambar 4. Kontur Akumulasi Konsentrasi Emisi Periode Musim Hujan dari Seluruh Sumber Titik

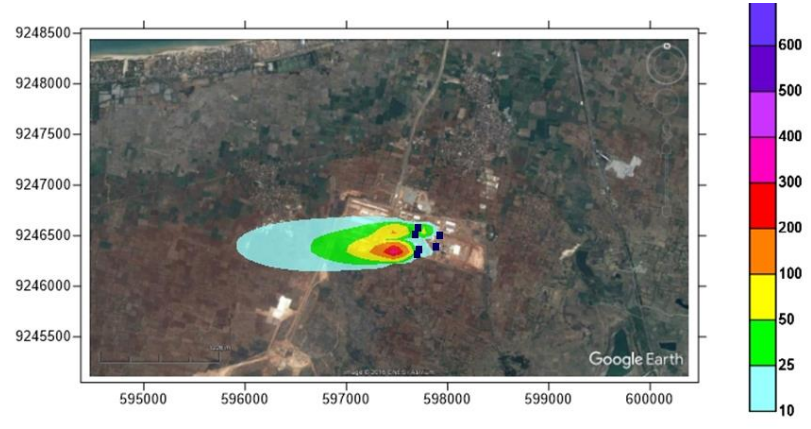

Gambar 5. Kontur Akumulasi Konsentrasi Emisi Periode Musim Kemarau dari Seluruh Sumber Titik

Dari Gambar 4 dan Gambar 5 dapat diihat bahwa polutan tersebar tidak jauh dari sumber emisi. Sebaran debu pada tinggi 1,5 meter dari permukaan tanah tersebar lebih luas di musim hujan.

\section{E. Tingkat Error Perhitungan Model}

Tingkat error perhitungan dilakukan dengan membandingkan hasil perhitungan model dan pengukuran lapangan. Nilai tingkat Erorr perhitungan model dapat dilihat pada Tabel 5.

Tabel 5.

Tingkat Error Perhitungan Model

\begin{tabular}{lccc}
\hline \hline Lokasi & $\begin{array}{c}\text { Konsentrasi } \\
\text { Ambien } \\
\left(\mathrm{mg} / \mathrm{Nm}^{3}\right)\end{array}$ & $\begin{array}{c}\text { Hasil Perhitungan } \\
\left(\mathrm{mg} / \mathrm{Nm}^{3}\right)\end{array}$ & Tingkat Error \\
\hline $\begin{array}{l}\text { Balai Desa } \\
\text { Sawir }\end{array}$ & 0,077 & 0,061 & $21 \%$ \\
Premix & 0,058 & 0,042 & $27 \%$ \\
Unit I & 0,051 & 0,010 & $80 \%$ \\
Plant Site & & & \\
\hline \hline
\end{tabular}

\section{KESIMPULAN}

1. Sebaran emisi berupa debu pada musim hujan dan musim kemarau paling tinggi cenderung terkumpul didekat sumber emisi dengan jarak $<1000 \mathrm{~m}$. Pola dispersi mengikuti arah angin dan sensitif terhadap stabilitas atmosfer. 
2. Konsentrasi maksimum debu selama enam bulan pada periode musim kemarau dengan kondisi meteorologi rata-rata kecepatan angin adalah $3,8 \mathrm{~m} / \mathrm{s}$ ke arah Barat serta suhu udara lingkungan $28,1 \mathrm{C}$ terletak pada titik koordinat $(597477,4 \mathrm{~m} ; 9246348 \mathrm{~m})$ dan elevasi muka tanah sebesar 28 mdpl adalah 444,26 $\mu \mathrm{g} / \mathrm{m} 3$. Konsentrasi maksimum debu selama enam bulan pada periode musim hujan dengan kondisi meteorologi rata-rata kecepatan angin adalah $3,6 \mathrm{~m} / \mathrm{s}$ ke arah Timur serta suhu udara lingkungan 27,4 C. terletak pada titik koordinat $(597877,4 \mathrm{~m} ; 9246348$ m) dan elevasi tanah $27 \mathrm{mdpl}$ adalah 547,24 $\mu \mathrm{g} / \mathrm{m} 3$. Emisi debu maksimum pada musim kemarau jatuh di wlayah industri.

\section{UCAPAN TERIMA KASIH}

Penulis mengucapkan terima kasih kepada Bapak Joni Hermana dan Bapak Abdu Fadli Assomadi atas bimbingan yang telah diberikan kepada saya selama proses penyusunan laporan tugas akhir maupun paper serta Direktorat Pendidikan Tinggi, Departemen Pendidikan dan Kebudayaan Republik Indonesia yang telah memberikan dukungan finansial melalui Beasiswa Bidik Misi tahun 2013-2017.

\section{DAFTAR PUSTAKA}

[1] A. Suryani, S., Gunawan dan Upe, "Model Sebaran Polutan SO2 pada Cerobong Asap PT Semen Tonasa," in Kongges dan Seminar Nasional Badan Koordinasi Pusat Studi Lingkungan Hidup seIndonesia ke XX, 2010.

[2] R. dan Hanley, "Aerosol Handbook Measurement, Dosimetry and Health Effects CRC press," 2005.

[3] H. J. Mukono, Prinsip Dasar Kesehatan Lingkungan Edisi Kedua. Surabaya: Airlangga University Press, 2006.

[4] S. Yulaekah, "Paparan Debu Terhirup dan Ganguan Fungsi Paru pada Pekerja Industri Batu Kapur," 2007.

[5] Meteotrend, "Perubahan Cuaca di Tuban," meteotrend.com, 2017. [Online]. Available: url:http://id.meteotrend.com/forecast/id/tuban.

[6] A. Visscher, Air Dispersion Modelling. New Jersey: John Willwy \& Sons Inc.H. Poor, 2014.

[7] H. Hassan, "Appilcation of Line Source Air Quality Model to The Study of Traffic Carbon Monoxida in Brunei Darussalam," ASEAN J. Sci. Technol. Dev., vol. 17, 2000.

[8] A. S.P, "Air Pollution Meteorology and Dispersion. Department of Marine Earth and Atmospheric," 1999.

[9] J. Assomadi, A.F., Widodo, B., Hermana, "The Kinetic Approach of NOx Photoreaction Related toGround Measurement of Solar Radiation in Estimates of Surface Ozone Concentration," Int. J. ChemTech Res., vol. 9, no. 7, pp. 182-190, 2016.

[10] T. Nauli, "Pola Sebaran Polutan Dari Cerobong Asap," in Prosiding Pertemuan dan Presentasilimiah Penelltlan Dasar IImu Pengetahuan dan Teknologl Nukllr P3TM-BATAN, 2002. 